\title{
An investigation into cracking in nickel-base superalloy repair welds
}

\author{
M.T. Rush ${ }^{* 1, a}$, P.A. Colegrove ${ }^{1, b}$, Z. Zhang ${ }^{2, c}$ and B. Courtot ${ }^{1,}$ \\ ${ }^{1}$ Welding Engineering Research Centre, Cranfield University, Mk43 OAL, United Kingdom \\ ${ }^{2}$ Doncasters Group Limited, Millennium Court, Burton-upon-Trent, DE14 2WR, United Kingdom \\ am.t.rush@cranfield.ac.uk*, ${ }^{b}$ p.colegrove@cranfield.ac.uk, ${ }^{c}$ z.zhang.irc@bham.ac.uk \\ ${ }^{*}$ Corresponding author
}

Keywords: Liquation cracking, Nickel Superalloy welds, Laser welding, Cold Metal Transfer, CMT, Strain age cracking, Rene 80

\begin{abstract}
The nickel-base superalloy Rene 80 is considered very susceptible to liquation and strain-age cracking. Material in the solutionised condition is welded using the Cold Metal Transfer, or CMT process (with ductile filler alloy) and autogenously using a laser. Grain size is shown to have a significant effect on cracking. Using the CMT, welding power is shown to have high significance on the level of cracking, whereas welding speed has little effect. When welding using the laser, it is shown that the power and spot size are more crucial to the material cracking than the travel speed. It is indicated that the weld bead geometry has high significance over the occurrence of cracking, with a relationship between welding power, weld bead geometry, and stresses controlling the occurrence and magnitude of cracking. Further, some laser welds are analysed after post-weld heat treatment, and there is a significant increase in cracking after this. However, $34 \%$ of samples contained no cracking in both the as-welded and post-weld heat treated state.
\end{abstract}

\section{Introduction}

Gas turbines are manufactured with a significant number of key components from superalloys, which are selected due to their excellent high temperature creep resistance given primarily by the precipitation strengthening by $\gamma$ ' precipitates and carbides, and also their equally excellent corrosion/oxidation resistance [1,2]. Due to the increasing cost of the material and high cost of producing such components, gas turbine original equipment manufacturers are investigating methods of repairing blades using fusion welding rather than replacement [3]. Unfortunately, superalloys, like other precipitation-hardening alloys, are susceptible to liquation cracking during welding and strain-age cracking after welding [4]. As a result, weld repairs on these materials often contain cracks so the components do not meet the required specification.

Liquation cracking is a welding defect that occurs in the heat-affected-zone (HAZ) of welds produced on superalloys, generally nucleating at the fusion boundary and propagating towards the base material. They are intergranular by nature and form along the grain boundaries. It has been reported [5] that liquation occurs by either:

- The constitutional liquation of secondary phase particles, or

- The segregation of melting point suppressant elements on grain boundaries during solidification of castings and subsequent thermal processing prior to welding

There has been significant research into liquation microfissuring in the alloy [6,7] which is considered one of the most HAZ crack susceptible superalloys. This work primarily focuses on determining the phases which form in the liquid film which cracks, with other work focusing on the effects of filler alloy composition [8,9]. In addition, it has been reported that the level of liquation cracking in an alloy is affected by the level of liquation, the grain structure (a coarser grain size leads to greater segregation of elements on grain boundaries), the ductility of the alloy (and therefore how the alloy resists the welding stresses) and the level of heat input (resulting in greater HAZ size and therefore greater area of liquation). 
The alloy of interest in this research is Rene 80, an alloy of similar composition to IN738 and also considered very susceptible to HAZ cracking and difficult to weld. The mechanism of liquation in this alloy has been reported previously [10] and found to be due the liquation of MC type carbides in a solutionised condition pre-weld, MC type carbides and $\gamma / \gamma^{\prime}$ eutectic islands in an ascast condition, and MC-type carbides and borides in an overaged condition. However, the solutionised condition had the lowest level of liquation due to reduced segregation of this phase.

In this work, liquation cracking has been investigated on the Rene 80 superalloy using the CMT welding process [11]. In addition, autogenous laser bead on plate welds have been performed on the same alloy to investigate the effects of different heat inputs on liquation cracking.

\section{Experimental procedure}

During the first stage of the experiments, a Fronius 3200 CMT power source is used, together with $1.6 \mathrm{~mm}$ IN625 filler alloy. Chemical analysis was performed to find the composition of the alloy, and is shown in table 1 for the $0.7 \mathrm{~mm}$ and $1.71 \mathrm{~mm}$ batch. See Table 1 for details of the chemical composition of the filler alloy IN625 used in the CMT experiments only. The parameters applied are outlined in table 2. Two different grain sizes were used for the CMT work to test the grain size effect, these are $3.5 \mathrm{~mm}$ and $4.9 \mathrm{~mm}$ average diameter.

For the second stage of the results reported, an IPG YLR-8000 high power fibre laser is used. This is an $\mathrm{Yb}$ doped fibre, operating an emission wavelength of $1070 \mathrm{~nm}$ with a spot focus diameter of $0.64 \mathrm{~mm}$ and a maximum power output of $8 \mathrm{~kW}$. The beam is delivered through a fibre optics system to a Precitec YW50 process head with a collimating focal length of $125 \mathrm{~mm}$ and a beam focal length of $250 \mathrm{~mm}$. The process head is mounted on a Fanuc M-170iB/45T robot.

Table 1 Chemical compositions (typical values) of base material and filler alloy (in \%)

\begin{tabular}{|l|l|l|l|l|l|l|l|l|l|}
\hline Material & Cr & Co & Mo & W & Al & Ti & C & B & Ni \\
\hline Rene 80 & 14 & 9 & 4 & 4 & 3 & 4.7 & 0.16 & 0.015 & Bal \\
\hline IN 625 & 23 & 1 & 10 & - & 0.4 & 0.4 & 0.1 & - & Bal \\
\hline
\end{tabular}

The material used for the laser trials was supplied in two batches, the first batch used for the 0.7 and $1.71 \mathrm{~mm}$ spot size welds and the post-weld heat treated analysis, and the second for the 2.5 and $5.0 \mathrm{~mm}$ welds. Therefore this is considered when analyzing the results. The average grain diameter of the material used in these welds is the $3.5 \mathrm{~mm}$ size. Four different spot sizes are used; they are $0.7,1.712 .5$ and $5.0 \mathrm{~mm}$. Also, a range of travel speeds from $50 \mathrm{~mm} / \mathrm{min}$ up to $4000 \mathrm{~mm} / \mathrm{min}$ are used to increase the heat input ranges further. Further, the welds performed using the 0.7 and 1.71 mm spot sizes are also treated with the standard post-weld solution heat treatment for this material.

Prior to welding, the $22 \mathrm{~mm}$ thick cast blocks of material are solutionised and then cleaned using a wire brush followed by wiping with acetone. After welding, the samples were sectioned transverse to the weld direction and ground and polished using standard metallographic procedures, with the samples then etched using a Kalling's waterless reagent $\left(2 \mathrm{~g} \mathrm{CuCl}_{2}, 40 \mathrm{ml} \mathrm{HCl}\right.$ and $80 \mathrm{ml}$ methanol). The microstructures are then analysed on a Nikon Optiphot microscope, and weld macros are taken using a Nikon Prysm system. All weld geometries and crack lengths are measured using Carl Zeiss Axiovision ${ }^{\circledR}$ software.

Table 2 - Summary of parameters applied in this investigation

\begin{tabular}{|l|l|l|}
\hline CMT & CMT Pulse mix & Laser \\
\hline Shielding gas: $\mathrm{Ar}+2.5 \% \mathrm{CO}_{2}$ & Shielding gas: $\mathrm{Ar}+2.5 \% \mathrm{CO}_{2}$ & High purity $\mathrm{Ar}$ \\
\hline Power $(\mathrm{W}): 2567-3416(4)$ & Power(W): $2272-5452(9)$ & Power $\mathrm{kW}: 0.4-8(16)$ \\
\hline Travel speeds (m/min) - 0.4 and 0.6 & Travel speed(m/min): 0.3 and 0.5 & Travel speed mm/min: $50-4000(11)$ \\
\hline Wire feed speed (m/min) - 6 and 6.5 & Pulses: 10 and 30 & Spot sizes (mm): 0.7, 1.7, 2.5 and 5.0 \\
\hline & $\begin{array}{l}\text { CMTs: } 1 \text { and } 5 \\
\text { Time at base }(\mathrm{ms}) 2 \text { and } 4\end{array}$ & \\
\hline
\end{tabular}

The laser results are analysed using the historical data function in Design Expert 7.1, due to difficulty in interpreting the results due to large amount of scatter in the data. Here, the data is input to determine the processing factors which had the most significant effect on the ACL (average crack 
length) for both types of process. The ACL values are used in preference to the total crack length (TCL) because the average values are less dependant on the weld bead size.

\section{Results}

a)
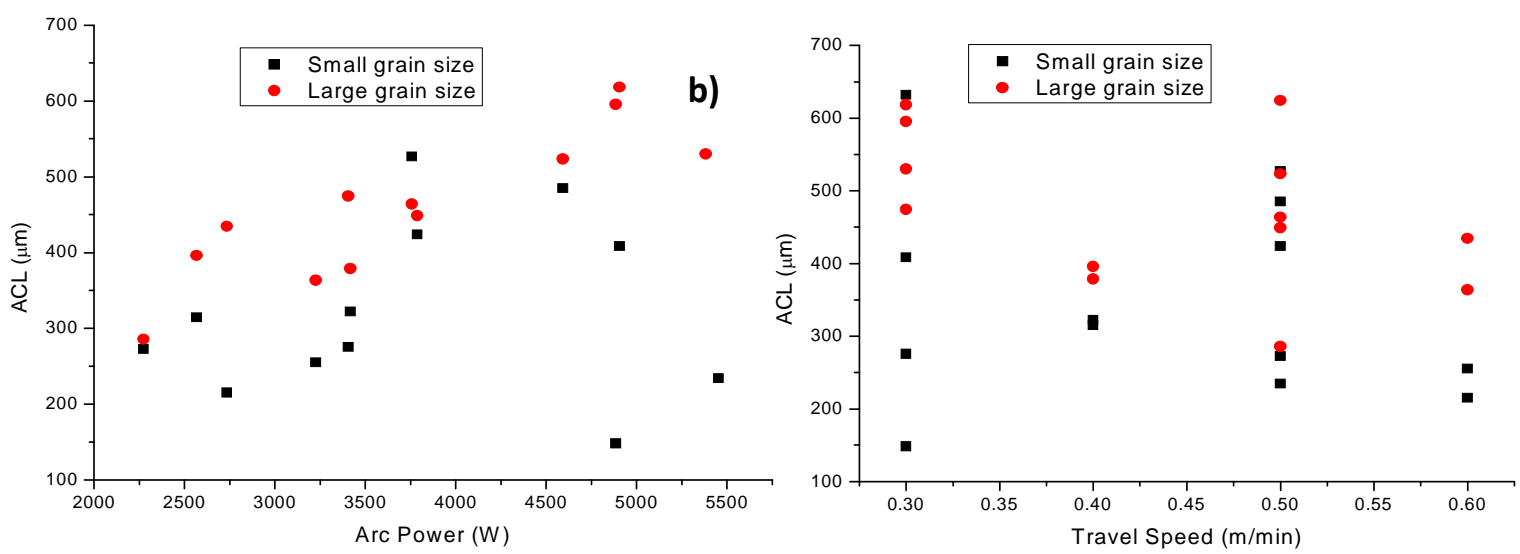

Figure 1 - Effect of a) arc power and b) travel speed on ACL using the CMT process.

a)

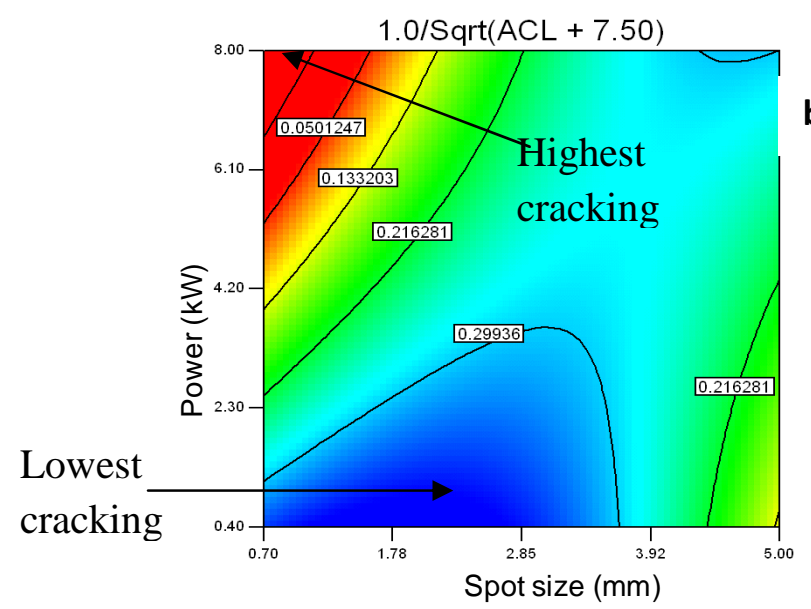

b)

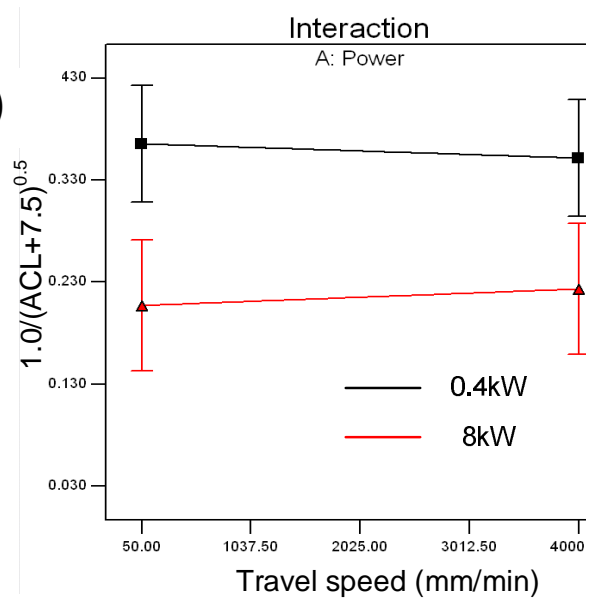

Figure 2 - Effect of a) Power and spot size and b) travel speed and power on ACL using the laser process.

a)

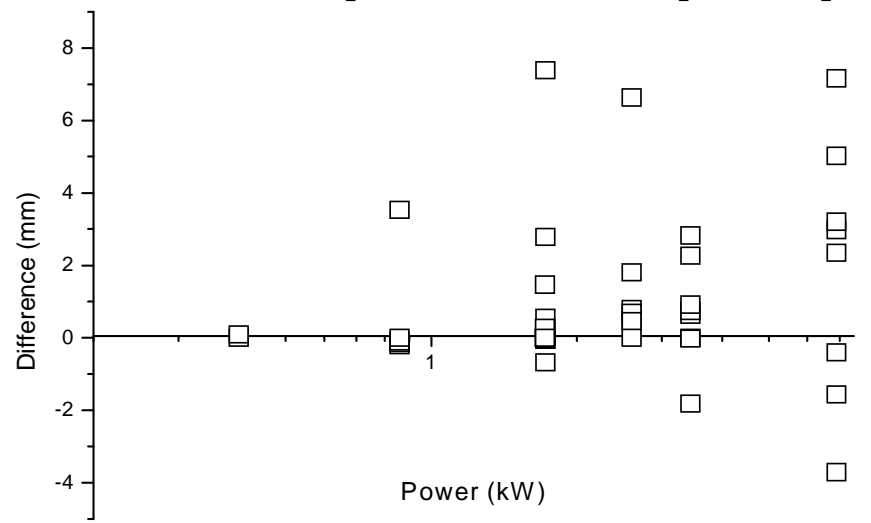

Cracking (Before - After)

b)

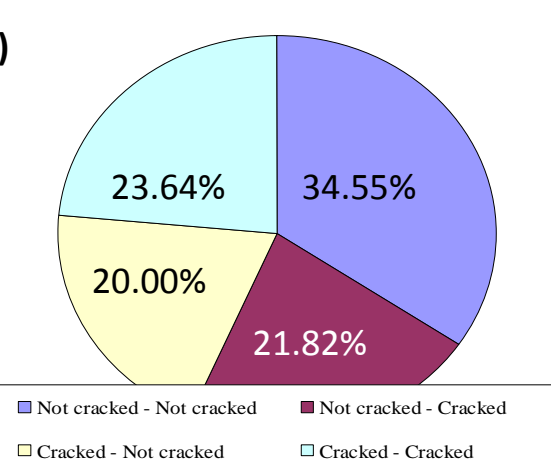

Figure 3 - A) the difference after PWHT of total crack length in laser welds 0.7 and $1.71 \mathrm{~mm}$, and b) changes in cracking before and after PWHT

Figure 1 shows the effects of arc power and travel speed on the average crack length for the CMT process. It shows that there is significant effect of increasing power on the cracking, whilst there is little effect of the travel speed. It also shows that there is a small effect of grain size, with the larger grain sized material showing more cracking compared to the smaller grain size.

A small number of the laser samples showed evidence of solidification cracking in the FZ. As a result, these samples are discounted from the results due to significantly increasing the length of cracking in the sample. Also, the presence of a solidification crack indicates that the surrounding material will have been relieved of stresses, and have a notable effect on the liquation cracking. 
The laser welding data showed significant scatter, and as a result the Design Expert V7 historical data function is used to help understand the factors. The factors used are: power, travel speed, and spot size. A quadratic model was selected which best fits the data, and was optimized to have the best significance.

$$
y^{\prime}=\frac{1}{\sqrt{A C L+7.5008}}
$$

Where ACL is the measured average crack length and 7.5008 is a constant.

An equation which describes the crack length is shown above. A diagram showing how this equation transforms the data is shown in figure 4.

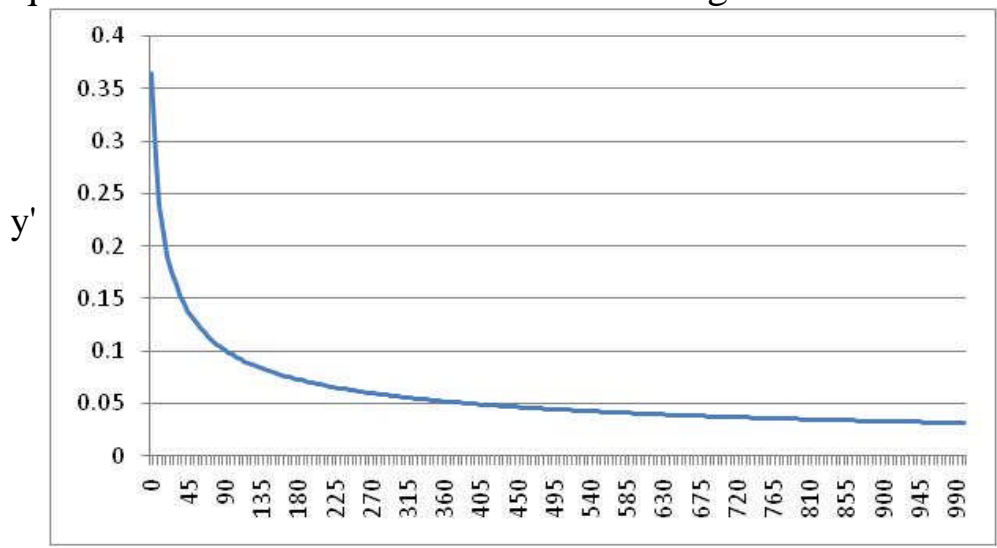

Figure 4 - Effect of transform (y-axis) on the ACL values (x-axis)

To determine whether a parameter is significant, the model variance is compared with residual error variance. This $\mathrm{F}$ value is a ratio, with the closer the value 1 indicating that the term does not have a significant effect on the response. The probability of the F-value occurring and being false is denoted with a probability less than $\mathrm{F}$ value, with values less than 0.05 being significant, and above 0.10 regarded as not significant. The analysis showed that power (0.0018), spot size (0.0357), , interaction between power and spot size $(<0.0001)$, interaction between spot size and travel speed $(0.0046)$ and the spot size squared $(<0.0001)$ are all significant.

$$
(A C L+7.50)^{-0.5}=0.29-0.072 * A+0.049 * C+0.16 * A * C-0.069 * B * C-0.12 * C^{2}
$$

Where $\mathrm{A}=$ power $(\mathrm{kW}), \mathrm{B}=$ travel speed $(\mathrm{mm} \min )$ and $\mathrm{C}=$ spot size $(\mathrm{mm})$

Figure $2 \mathrm{a}$ shows a contour plot of $\mathrm{y}^{\prime}$ vs power and spot size, and figure $2 \mathrm{~b}$ shows a plot of $\mathrm{y}^{\prime}$ vs. insignificant; as with the CMT data. A second analysis was performed without the transform applied which indicated some effect of the travel speed, with the effect being smaller at low powers than high powers. Figure 2a shows that with small spot sizes, the power has a significant effect on the cracking, whist at larger spot sizes the effect is negligible.

Figures $3 \mathrm{a}$ and $3 \mathrm{~b}$ illustrate the distribution of the cracking after the post-weld heat treatment (PWHT) was applied to the TCL data from the $0.7 \mathrm{~mm}$ and $1.71 \mathrm{~mm}$ spot sizes only. Firstly, the difference after the heat treatment in cracking is shown in figure 3a. Clearly, there are a significant number of samples which showed a change in cracking after the heat treatment, with $1 / 3^{\text {rd }}$ of all samples containing no cracks in both the as-welded and post-weld heat treated state. Figure $3 \mathrm{~b}$ shows how the samples were divided into four categories: no cracking before and after heat treatment, no cracking before but cracking afterwards, a reduction in cracking after the heat treatment, and finally an increase in cracking (where there was cracking already).

\section{Discussion}

It is clear from figure 1a that for the CMT process, power has a significant effect on the ACL, for both grain sizes. This is as a result of greater energy being input, causing both a greater region of area susceptible to liquation, but also having an impact on the weld bead geometries and the stresses within it. It is also clear from both figures $1 \mathrm{a}$ and $1 \mathrm{~b}$, that there is a significant effect of the material 
grain size. The larger grain sized material shows more cracking which is as expected, and is a result of the lower ductility, and also likely increased segregation of liquating phases.

Figure 2 illustrates the difference in the significance of both power and spot size on the cracking. At lower spot sizes, the power has high significance, which is due to higher intensities causing the weld bead geometry to have significantly higher penetration, often with narrower welds. At the larger spot sizes, the power has less of significance, with higher power welds having very little cracking, whereas there is actually slightly more cracking with the low powers. The weld bead geometries under these parameters are very wide but shallow. The geometries of the weld beads at both the low power small spot size, and high power large spot size parameters are very similar; of almost uniform penetration and width. This indicates that there is an optimum weld bead geometry for which cracking will be minimised

Another noteworthy finding from this plot is the optimum value of spot size yielding the lowest cracking at approximately 2.5 to $3 \mathrm{~mm}$. This finding however maybe the result of either a material difference, or processing. For instance, the same pre-welding preparation - such as shot blasting, wire-brushing and wiping was applied to all material- but there may be an irregularity in any one of these steps that were applied to the blocks on which the $2.5 \mathrm{~mm}$ welds are performed. It is believed that this is the less likely of the two explanations, and that it is more likely a difference in materials composition or material microstructure - such as being more homogenous and containing less segregation.

Nevertheless if this optimum value of spot size is correct, then this confirms that there may be a significance in the weld bead geometry having effects on the levels of cracking in the welds, with welds that are of very similar penetration to width having no cracking, but welds which have either significantly greater penetration than width, or vice versa, showing higher cracking.

This then suggests that there is a relationship between welding processes, weld bead geometry, and stresses on the cracking. As a result, a point of interest for further work is to model the stresses developed in the different weld bead profiles and understand further their role in the occurrence of cracking.

The inverse square root which is applied to the welding speed data acts to condense the cracked data, particularly where significant cracking has occurred. For example figure 4 shows very little change in the transformed value occurred for ACL values between 200 and 700. Therefore the transform helps to show where cracking does and does not occur.

The welding speed for both processes (figure $1 \mathrm{~b}$ and $2 \mathrm{~b}$ ) showed little or no effect on the cracking, which is an interesting finding. The welding speed is likely to influence the extent of liquation. For example low speeds will increase the conductive heat transfer into the material and the amount of grain boundary melting. Both CMT and laser results have indicated negligible effect of the travel speed and therefore the extent of the liquation. Hence as discussed previously cracking is likely to be affected more by the stresses generated and the shape of the weld bead rather than the extent of the liquation.

Note however, that a small effect of travel speed was observed when the transformation was not used. As mentioned previously the transform compresses the data where cracking has occurred. Therefore where cracking occurs, the size of the cracks is increased by reducing the travel speed.

After the post-weld heat treatment is applied, there is a significant increase in the cracking found in the measured samples. It should firstly be illustrated that the total crack length (TCL) values are used rather than the ACL, because the ACL showed a reduction in cracking caused by the nucleation of smaller cracks, which increased the total number of cracks. As a result, the TCL showed more accurately the change in cracking caused by this heat treatment. The increase in cracking is caused by the nucleation of new cracks via the strain-ageing mechanism, as well as the propagation of existing cracks.

Figure 3a shows that as power is increased; the total amount of cracking after the heat treatment increases significantly, whereas at lower powers this change is not as dramatic. Also, where there is no cracking before, there is a significant chance that there will be no cracking afterwards. In fact, as shown by figure $3 \mathrm{~b}$, there is a $34.5 \%$ chance of this statement occurring. In total, there is a $61 \%$ (35/ 
$(35+22))$ chance of a weld containing no cracks after post-weld heat treatment if it has contained no cracking in the as-welded state, However, $20 \%$ of all samples showed a reduction in TCL after the heat treatment, which is quite an interesting result, although it should be remember that there was a large amount of scatter in the results.

\section{Conclusions}

When welding nickel-based superalloys, cracking occurs through liquation, and after welding via strain-age cracking. The welding power has significance on both the occurrence and magnitude of cracking, with low powers minimising cracking with a small spot size and high powers minimising cracking with a large spot size, which indicates that the weld bead geometry has an effect on the occurrence of cracking. There is an optimum value of spot size at approximately 2.5 to $3.0 \mathrm{~mm}$ where cracking is minimized. The effects of welding speed are shown to be negligible for both processes. This is an interesting result as it indicates it is not necessary to weld at higher travel speeds. It is shown that the key relationship between welding power, geometry of weld bead, and stresses with the cracking is important and future work will investigate this relationship, utilizing modelling and residual stress measurements.

Post-weld heat treatment is shown to have a substantial increase in cracking, as a result of the nucleation of cracks and the propagation of existing ones. It is shown that $35 \%$ of welds had no cracking before and after the heat treatment was applied to the welds, and that there is a $61 \%$ change of no cracking occurring in a sample after post-weld heat treatment if the sample contains no cracking in the as welded condition.

\section{Acknowledgements}

The authors wish to acknowledge the support of Doncasters Precision Castings Deritend, part of the Doncasters Group Plc for the financial support given to the project which this work is part of. The Authors also acknowledge the support of the EPSRC for further support of the PhD CASE studentship.

\section{References}

[1] Donachie MJ, Donachie SJ. Superalloys: a technical guide. 2nd ed. Materials Park,OH: ASM International; 2002.

[2] Reed RC. The superalloys : fundamentals and applications. Cambridge: Cambridge University Press; 2006.

[3] Henderson MB et al . Nickel based superalloy welding practices for industrial gas turbine applications. Science and Technology of Welding and Joining 2004;9(1):13-21.

[4] Kou S. Solidification and liquation cracking issues in welding. JOM 2003;55(6):37-42.

[5] Chaturvedi MC, Liquation cracking in heat affected zone in Ni superalloy welds, Materials Science Forum Vol 546-549, pp 1163-1170; 2007.

[6] Ojo OA, et al. Study of the fusion zone and heat-affected zone microstructures in tungsten inert gas-welded INCONEL 738LC superalloy. Metallurgical and Materials Transactions A: 2006;37(2):421-433.

[7] Ojo OA. Intergranular liquation cracking in heat affected zone of a welded nickel based superalloy in as cast condition. Materials Science and Technology 2007;23(10):1149-1155.

[8] Sidhu RK, Richards NL, Chaturvedi MC. Effect of aluminium concentration in filler alloys on HAZ cracking in TIG welded cast lnconel 738LC superalloy. Materials Science and Technology 2005;21(10):1119-1131.

[9] Banerjee K, Richards NL, Chaturvedi MC. Effect of filler alloys on heat-affected zone cracking in preweld heat-treated IN-738 LC gas-tungsten-arc welds. Metallurgical and Materials Transactions A: Physical Metallurgy and Materials Science 2005;36(7):1881-1890.

[10] Shahsavari HA, Kokabi AH, Nategh S. Effect of preweld microstructure on HAZ liquation cracking of Rene 80 superalloy. Materials Science and Technology 2007;23(5):547-555.

[11] Pickin CG, Young K. Evaluation of cold metal transfer (CMT) process for welding aluminium alloy. Science and Technology of Welding and Joining 2006;11(5):583-585. 